\title{
A Survey Study on Professional Women's Perception toward Cosmetic Surgery: 4 Year Comparison
}

\author{
Seonsik Yun ${ }^{1}$, Youngcheon $\mathrm{Na}^{1,2}$, \\ Youngwan Jin ${ }^{1}$, Eunsuk Hur ${ }^{1}$, \\ Woohoe Heo ${ }^{1}$, Jeongmi Lee ${ }^{2}$, \\ Seoul Lee ${ }^{2}$
}

${ }^{1}$ Department of Plastic and Reconstructive Surgery, Wonkwang University School of Medicine, Iksan; ${ }^{2}$ Wonkwang Medical Institute, Wonkwang University School of Medicine, Iksan, Korea
No potential conflict of interest relevant to this article was reported.
Background The popular demand for cosmetic surgery is increasing explosively, but little is known about how perceptions of cosmetic surgery among women are related to demographics or psychological factors. A survey was conducted to compare changes in perception about cosmetic surgery among professional women in 2010 and 2014. Methods A questionnaire-based survey was performed at a general hospital by female nurses in 2010 and 2014. Participants included 350 women in 2010 and 470 women in 2014; 323 individuals in 2010 and 449 individuals in 2014 completed the survey (overall response rates of $92.3 \%$ and $95.5 \%$, respectively). Participants identified their demographic data, which included age, educational level, marital status, monthly income, and previous experience with cosmetic surgery. The survey included standardized measures for appearance interest, body image satisfaction, self-esteem, and perceptions toward cosmetic surgery (delineated in terms of actual considerations).

Results Compared to 2010, actual considerations for cosmetic surgery were higher in 2014, specifically for women in their 20s, a monthly income between 2 to 3 million won, and those with high scores of self-esteem, appearance interest, and body image satisfaction.

Conclusions In this study, in order for professional women to undergo appropriate cosmetic surgery and be satisfied with the results, it is necessary to obtain a deeper understanding about the factors that influence the perceptions of cosmetic surgery.

Keywords Data collection, Perception, Surgery plastic, Women

\section{INTRODUCTION}

Cosmetic surgery is increasingly popular around the world. Korea is gaining a reputation as a cosmetic surgery mecca. Based on statistics compiled by the International Society of Aesthetic Plastic Surgeons, South Korea had 649,938 cosmetic surgery procedures performed in 2011, representing a 22.4\% increase from 2010 [1]. This number, divided by its 2011 population, reflects 13.5 people

Received: May 18, 2015 Revised: Jun 1, 2015 Accepted: Jun 1, 2015 Correspondence: Youngcheon Na Department of Plastic and Reconstructive Surgery, School of Medicine, Wonkwang University, 895 Muwang-ro, Iksan 570-711, Korea. E-mail: ycnadr@hanmail.net

Copyright @ 2015 The Korean Society for Aesthetic Plastic Surgery.

This is an Open Access article distributed under the terms of the Creative Commons Attribution Non-Commercial License (http://creativecommons.org/licenses/by-nc/3.0/) which permits unrestricted non-commercial use, distribution, and reproduction in any medium, provided the original work is properly cited. www.e-aaps.org out of 1,000 individuals, according to a report from the Economist Online [2].

In line with the growing popularity of cosmetic surgery, many studies have been presented in Western countries. To explain the rise of the demand for cosmetic surgery, Rohrich [3] suggested improved safety and an increasing desire to appear youthful. Sarwer et al. [4] presented the medical advances and suggested that the influence of the mass media has attributed to this increase. Henderson-King and Henderson-King [5] examined the relationships between the perceptions about cosmetic surgery, an individual's relationships, and the social environment. Crockett et al. [6] showed that exposure to the media plays a significant role in the perceptions that patients have about cosmetic surgery.

In recent research, psychological factors have been proposed to be important in the decision to undergo cosmetic surgery. Brown et al. [7] reported a strong correlation with an individual's low selfrated attractiveness. von Soest et al. [8] also showed that consider- 
ing cosmetic surgery is strongly related to self-esteem, social acceptance, and body image.

Despite significant studies in Western countries, very little research exits in South Korea that is related to the perceptions about cosmetic surgery. For this reason, Western studies have limited applications in East-Asian nations. The current study aimed to analyze the influences of demographics and psychological factors on perceptions about cosmetic surgery among professional women who have a greater level of expertise, and frequent interpersonal relations.

\section{METHODS}

\section{Participants}

Questionnaire-based surveys were carried out by female nurses working in a general hospital in April 2010 and April 2014. Participants included 350 women in 2010 and 470 women in 2014; 323 individuals in 2010 and 449 individuals in 2014 completed the surveys (overall response rates of $92.3 \%$ and $95.5 \%$, respectively). The participants ranged in age from 20 to 49 years.

\section{Materials and measures}

The demographic data included age, education level, marital status, monthly income, and previous history of cosmetic surgery. The participants were also asked about their appearance interest, body image satisfaction, and self-esteem.

\section{Appearance interest}

The appearance evaluation subscale of multidimensional body-self relations questionnaire (MBSRQ) was used to measure appearance interest [9]. This 7-item questionnaire was answered using a 5-point Likert scale, from 1 to 5 ( 1 =strongly disagree, $5=$ strongly agree). Higher scores represented higher appearance interest.

\section{Body image satisfaction}

The body area satisfaction subscale of MBSRQ was used to assess participants' body image satisfaction [9]. The 12-item scale used a 5-point Likert scale ( 1 = strongly dissatisfied, $5=$ strongly satisfied). Higher scores indicated higher body image satisfaction.

\section{Self-esteem}

The Rosenberg self-esteem Scale is a measure consisting of 10 items, in which items are answered using a 5-point Likert scale ( $1=$ strongly disagree, $5=$ strongly agree) [10]. Higher overall scores mean a higher self-esteem.

\section{Perception toward cosmetic surgery}

To measure the participants' actual considerations about undergoing cosmetic surgery, we used the actual consideration scale based on a non-Western standard. This 3-item scale included items, such as "I would seriously consider having a cosmetic surgery in order to look more attractive," "I would undergo cosmetic surgery to be in a good shape," and "If I can gain confidence in my body through cosmetic surgery, I would like to try it." Items were rated using a 5 -point Likert scale ( 1 = strongly disagree, 5 = strongly agree). Higher scores represent a greater tendency to undergo cosmetic surgery.

\section{Procedure}

The questionnaires were collected and results were calculated using SPSS 12 (SPSS Inc., Chicago, IL, USA). An $\chi^{2}$-test or t-test was used to analyze perceptions about cosmetic surgery in 2010 and 2014, according to demographics and psychological factors. We also performed an independent $t$-test to measure differences between 2010 and 2014.

\section{RESULTS}

In 2010, the age distribution included $38.7 \%$ in their 20 s, $34.1 \%$ in their 30 s, and $27.2 \%$ in their 40 s; $52.6 \%$ completed college, $37.8 \%$ graduated university, and $9.6 \%$ had a postgraduate degree. The majority were married (51.7\%). With regard to monthly income, $20.1 \%$ earned 1.0 to 1.9 million won, $61 \%$ earned 2.0 to 2.9 million won, and $18.9 \%$ earned 3.0 to 3.9 million won; $40.9 \%$ had a past history of cosmetic surgery.

In 2014, the age distribution included $43 \%$ in their 20 s, $31.8 \%$ in their 30 s, and $25.2 \%$ in their 40 s; $48.3 \%$ completed college, $44.5 \%$ graduated university, and $7.1 \%$ had a postgraduate degree. The majority were unmarried (54.8\%). With regard to monthly income, $13.4 \%$ earned 1.0 to 1.9 million won, $65.9 \%$ earned 2.0 to 2.9 million won, and $20.7 \%$ earned 3.0 to 3.9 million won; $60.1 \%$ had a past history of cosmetic surgery (Table 1). Accordingly, 2010 and 2014 participants had similar demographic factors except monthly income.

Table 1. Participant demographic data

\begin{tabular}{clrrl}
\hline & & $2010(\mathrm{yr})$ & $2014(\mathrm{yr})$ & P-value \\
\hline Age in years, & $20-29$ & $125(38.7)$ & $193(43)$ & 0.49 \\
$\mathrm{n}(\%)$ & $30-39$ & $110(34.1)$ & $143(31.8)$ & \\
& $40-49$ & $88(27.2)$ & $113(25.2)$ & \\
Education level, & College & $170(52.6)$ & $217(48.3)$ & 0.125 \\
$\mathrm{n}(\%)$ & University & $122(37.8)$ & $200(44.5)$ & \\
& Postgraduate & $31(9.6)$ & $32(7.1)$ & \\
Marital status, & Marital status & $156(48.3)$ & $246(54.8)$ & 0.075 \\
$\mathrm{n}(\%)$ & Single & $167(51.7)$ & $203(45.2)$ & \\
Monthly income, & $1-1.9$ million won & $65(20.1)$ & $60(13.4)$ & 0.042 \\
$\mathrm{n}(\%)$ & $2-2.9$ million won & $197(61)$ & $296(65.9)$ & \\
& $3-3.9$ million won & $61(18.9)$ & $93(20.7)$ & \\
Previous experi- & No & $191(59.1)$ & $270(60.1)$ & 0.78 \\
ence with cos- & Yes & $132(40.9)$ & $179(39.9)$ & \\
metic surgery, & & & & \\
n (\%) & & & & \\
\hline
\end{tabular}


Average self-esteem was statistically higher in 2010 than in 2014 $(\mathrm{P}<0.05)$. There were no statistically significant differences in average appearance interest and body image satisfaction between 2010 and 2014 (Table 2).

Average actual considerations about undergoing cosmetic surgery were statistically higher in 2010 than in $2014(\mathrm{P}<0.05)$ (Table 3$)$.

Average actual considerations about undergoing cosmetic surgery were higher in those in their 30 s who earned 2 to 2.9 million won per month in 2010 than in $2014(\mathrm{P}<0.05)$. There were no significant differences in education level, marital status, and previous experience with cosmetic surgery (Table 4).

Average actual considerations about undergoing cosmetic surgery were higher in those with high appearance interest, body image satisfaction, and self-esteem in 2014 than in $2010(\mathrm{P}<0.05)$ (Table 5).

Table 2. Participant psychologic data

\begin{tabular}{lrrc}
\hline Variables & 2010 (yr) & 2014 (yr) & P-value \\
\hline Appearance interest & $3.4 \pm 0.52$ & $3.37 \pm 0.47$ & 0.474 \\
Body image satisfaction & $2.86 \pm 0.58$ & $2.85 \pm 0.56$ & 0.754 \\
Self-esteem & $3.60 \pm 0.49$ & $3.52 \pm 0.49$ & 0.023 \\
\hline
\end{tabular}

\section{DISCUSSION}

The main purpose of this study was to examine recent changes in perception toward cosmetic surgery in professional women. With regard to perceptions about cosmetic surgery by age, those in their 30s showed more actual consideration in 2014 than in 2010. This shows a strong correlation with age. Fogel and King [11] found that as one's age increases, one's appearance become less attractive, leading to increased interest in cosmetic surgery. Frederick et al. [12] reported that older women may experience added pressure to undergo surgery because they feel they are competing with younger women for the attention of their current or potential romantic partner. Recent trends indicate that baby face fever is not limited to

Table 5. Actual consideration in relation to psychologic factor

\begin{tabular}{lllll}
\hline & & 2010 (yr) & 2014 (yr) & P-value \\
\hline \multirow{2}{*}{ Appearance interest } & Higher than 3.6 & $2.99 \pm 0.90$ & $3.20 \pm 0.90$ & 0.023 \\
& Lower than 3.6 & $3.22 \pm 0.71$ & $3.28 \pm 0.77$ & 0.433 \\
Body-image satisfaction & Higher than & $3.29 \pm 0.87$ & $3.53 \pm 0.78$ & 0.005 \\
& Lower than & $2.90 \pm 0.73$ & $2.99 \pm 0.80$ & 0.256 \\
Self-esteem & Higher than & $2.99 \pm 0.80$ & $3.16 \pm 0.80$ & 0.035 \\
& Lower than & $3.20 \pm 0.84$ & $3.36 \pm 0.88$ & 0.084 \\
\hline
\end{tabular}

Table 3. Participant actual consideration toward cosmetic surgery

\begin{tabular}{|c|c|c|c|}
\hline Item & 2010 (yr) & 2014 (yr) & P-value \\
\hline I would seriously consider having a cosmetic surgery in order to look more attractive & $3.21 \pm 0.88$ & $3.33 \pm 0.88$ & 0.062 \\
\hline I would undergo cosmetic surgery to be in a good shape & $2.95 \pm 0.95$ & $3.12 \pm 0.95$ & 0.014 \\
\hline If I can gain confidence on my body through cosmetic surgery, I would like to try it & $3.14 \pm 0.89$ & $3.28 \pm 0.91$ & 0.034 \\
\hline Total score & $3.1 \pm 0.83$ & $3.24 \pm 0.84$ & 0.018 \\
\hline
\end{tabular}

Table 4. Actual consideration in relation to demographic factor

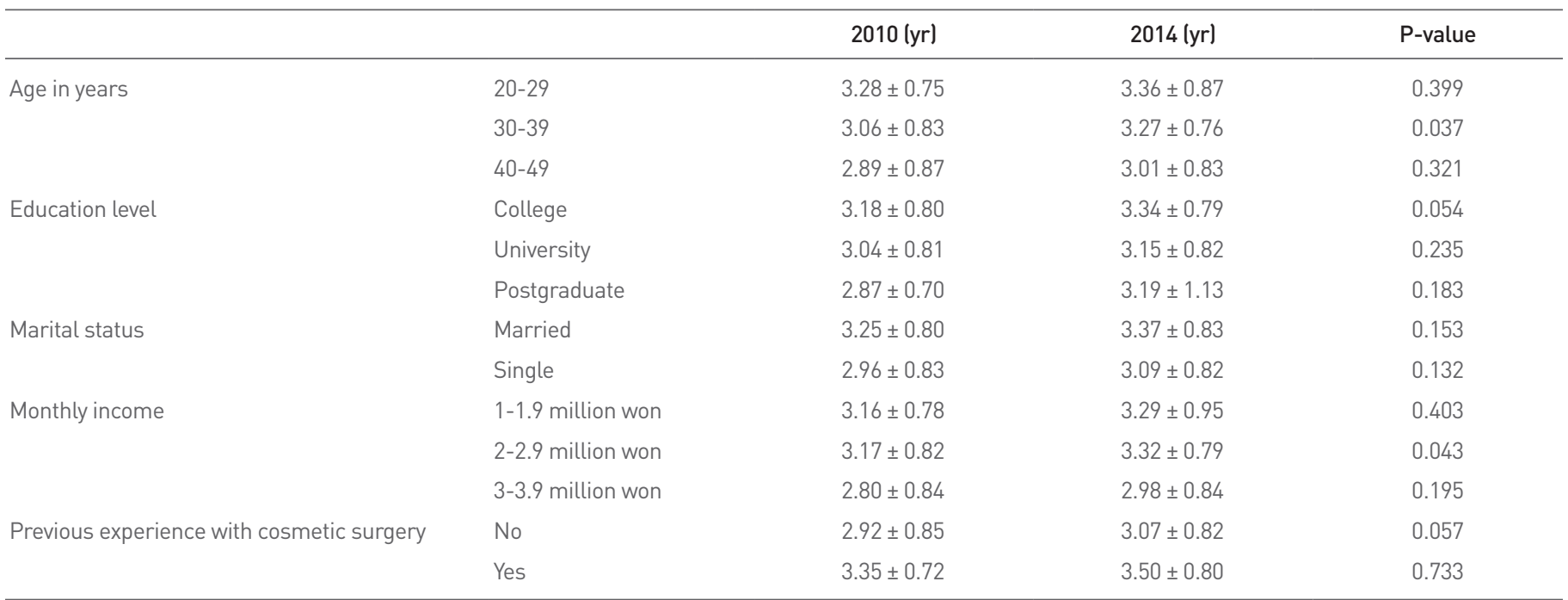


those in their 20s but has expanded to older ages, consistent with this result.

There were no statistically significant differences in perceptions about cosmetic surgery after considering the education level. This result is likely caused by the fact that appearance image management is greatly perceived in one's social life, regardless of academic ability. There were also no statistically significant differences in examined perceptions about cosmetic surgery that depended on marriage.

Actual considerations of undergoing cosmetic surgery by women who had a monthly income of 2.0 to 2.9 million won increased in 2014 and are thought to be in the same context as increased consumer spending, and as away to seek improvements in living quality due to increasing income level; consequently, the cosmetic surgery market is being expanded. We also found that actual considerations of women who have experienced cosmetic surgery were increased in 2014, similar to the study by Swami et al. [13], in which cosmetic surgery experiences predict perceptions about cosmetic surgery. This shows continuously increasing efforts and perceptions about appearance management over time.

Those with high self-esteem showed higher actual considerations in 2014 than in 2010. This result conflicts with that of Ahn et al. [14], who found that people want cosmetic surgery to recover confidence, and that of Furnham and Levitas [15], who found that people with low self-esteem are likely to seek more cosmetic surgery. This result fits with that of Chen et al.s study [16], indicating that those who seek more cosmetic surgery had higher self-esteem. This indicates that the recent atmosphere has been greatly reversed, as low self-esteem was previously a primary motivation for cosmetic surgery in the past.

Actual considerations in those with high appearance interest were statistically higher in 2014, consistent with the current trend showing that increasing demand is associated with increasing cosmetic surgeries.

Those with higher body satisfaction had higher actual consideration in 2014 than in 2010. This result conflicts with von Soest et al.s study [8], which found that body image is one of the strongest motivations to undergo cosmetic surgery. This result also differs from the studies by Furnham and Levitas [15] and Chen et al. [16], who indicate that low body satisfaction is one of the most significant variables to influence the desire to undergo cosmetic surgery. This implies that the correlation between body satisfaction and cosmetic surgery is not as strong as before.

Our study was limited by several factors, including the small population size, same sex, and occupation. Additionally, the use of an invalidated questionnaire should not be over generalized. It would be more helpful to identify statistically significant factors if the number and ages of study subjects were increased and the questions were made more applicable to various occupational groups. To reflect the reality that expanding mass media, social networking site
(SNS), and various advertisements greatly affect Korean society, follow-up studies about related independent factors are required.

The present study showed that those in their 30s, with a monthly income of 2.0 to 2.9 million won, and higher self-esteem, appearance interest, and body satisfaction were positively associated with perceptions about cosmetic surgery. Plastic surgeons should fully understand these changing perceptions to assess appropriate candidates and maximize with their results.

\section{REFERENCES}

1. International Society of Aesthetic Plastic Surgery. ISAPS international survey on aesthetic/cosmetic procedures performed in 2011 [Internet]. Hanover, NH: International Society of Aesthetic Plastic Surgery; 2011 [cited 2015 March 1]. Available from: http://www.isaps.org/Media/Default/global-statistics/ISAPS-Results-Procedures-2011.pdf.

2. The Economist. Plastic makes perfect [Internet]. London, UK: The Economist Newspaper Limited 2015; 2013 [cited 2015 March 1]. Available from: http://www.economist.com/blogs/graphicdetail/2013/01/ daily-chart-22.

3. Rohrich RJ. The increasing popularity of cosmetic surgery procedures: a look at statistics in plastic surgery. Plast Reconstr Surg 2000;106:1363-5.

4. Sarwer DB, Grossbart TA, Baker AW. Understanding the cosmetic surgery patient. In: Kaminer MS, Arndt KA, Dover JS, et al., editors. Atlas of cosmetic surgery. 2nd ed. Philadelphia, PA: Saunders; 2009. p.3-9.

5. Henderson-King D, Henderson-King E. Acceptance of cosmetic surgery: scale development and validation. Body Image 2005;2:137-49.

6. Crockett RJ, Pruzinsky T, Persing JA. The influence of plastic surgery "reality TV" on cosmetic surgery patient expectations and decision making. Plast Reconstr Surg 2007;120:316-24.

7. Brown A, Furnham A, Glanville L, et al. Factors that affect the likelihood of undergoing cosmetic surgery. Aesthet Surg J 2007;27:501-8.

8. von Soest T, Kvalem IL, Skolleborg KC, et al. Psychosocial factors predicting the motivation to undergo cosmetic surgery. Plast Reconstr Surg 2006;117:51-62.

9. Cash TF. Manual for the multidimensional body-self relations questionnaire [Internet]. Naples, FL: Body Images Research Consulting; 2000 [cited 2015 March 1]. Available from: http://www.body-images. com/assessments/mbsrq.html.

10. Rosenberg M. Society and the adolescent self-image. Princeton, NJ: Princeton University Press; 1965.

11. Fogel J, King K. Perceived realism and Twitter use are associated with increased acceptance of cosmetic surgery among those watching reality television cosmetic surgery programs. Plast Reconstr Surg 2014;134: 233-8.

12. Frederick DA, Lever J, Peplau LA. Interest in cosmetic surgery and body image: views of men and women across the lifespan. Plast Reconstr Surg 2007;120:1407-15.

13. Swami V, Chamorro-Premuzic T, Bridges S, et al. Acceptance of cos- 
metic surgery: personality and individual difference predictors. Body Image 2009;6:7-13.

14. Ahn KY, Chang JH, Park DH, et al. The cognition study of the freshman in college about aesthetic plastic surgery. J Korean Soc Plast Reconstr Surg 2005;32:161-7.
15. Furnham A, Levitas J. Factors that motivate people to undergo cosmetic surgery. Can J Plast Surg 2012;20:e47-50.

16. Chen HC, Karri V, Yu RL, et al. Psychological profile of Taiwanese female cosmetic surgery candidates: understanding their motivation for cosmetic surgery. Aesthetic Plast Surg 2010;34:340-9. 